\title{
Vitamin D metabolites and binding protein predict preeclampsia in women with Type 1 diabetes: a cohort study
}

\author{
Clare Kelly $^{1}$, Carol Wagner ${ }^{1}$, Judy Shary ${ }^{1}$, Misti Leyva ${ }^{1}$, Jeremy Yu ${ }^{1}$, Alicia Jenkins ${ }^{2}$, \\ Alison Nankervis ${ }^{3}$, Kristian Hanssen ${ }^{4}$, Satish Garg ${ }^{5}$, James Scardo ${ }^{6}$, Samar Hammad ${ }^{1}$, \\ Christopher Aston ${ }^{7}$, and Timothy Lyons ${ }^{1}$ \\ ${ }^{1}$ Medical University of South Carolina \\ ${ }^{2}$ University of Sydney \\ ${ }^{3}$ Royal Women's Hospital \\ ${ }^{4}$ Oslo University Hospital \\ ${ }^{5}$ University of Colorado \\ ${ }^{6}$ Spartanburg Regional Medical Center \\ ${ }^{7}$ The University of Oklahoma Health Sciences Center
}

May 21, 2020

\begin{abstract}
Objective: Preeclampsia (PE) occurs about four times more frequently in women with than without diabetes. Vitamin D is essential for healthy pregnancy. We investigated detailed measures of maternal plasma 25-hydroxyvitamin $\mathrm{D}(25(\mathrm{OH}) \mathrm{D})$, 1,25-dihydroxyvitamin $\mathrm{D}\left(1,25(\mathrm{OH})_{2} \mathrm{D}\right)$, and vitamin $\mathrm{D}$ binding protein (VDBP) to define associations with PE in women with Type 1 diabetes (T1DM). Design and setting: A multicentre prospective study in women at $12, \sim 22$ and 32 weeks' gestation ('Visits' (V) 1, 2, and 3, respectively). Population: We studied 23 T1DM women who subsequently developed PE, 24 who remained normotensive, and 19 non-diabetic, normotensive women (reference controls). Diabetic women were complication-free at V1, and all study visits preceded PE onset. Main Outcome Measures: Total, bioavailable, and free concentrations of 25(OH)D and $1,25(\mathrm{OH})_{2} \mathrm{D}$; and VDBP. Results: $25(\mathrm{OH}) \mathrm{D}$ deficiency was more frequent in diabetic than non-diabetic women $(69 \% \mathrm{vs}$ $22 \%, \mathrm{p}<0.05)$, but no measure of $25(\mathrm{OH}) \mathrm{D}$ predicted PE. In contrast, higher $1,25(\mathrm{OH})_{2} \mathrm{D}$ concentrations at V2 (total and bioavailable: $\mathrm{p}<0.01$; free: $\mathrm{p}<0.05$ ) and V3 (bioavailable: $\mathrm{p}<0.05$; free: $\mathrm{p}<0.01$ ) were associated with subsequent $\mathrm{PE}$ in T1DM women, as were lower concentrations of VDBP at V3 $(\mathrm{p}<0.05)$ and elevated ratios of 1,25(OH $)_{2} \mathrm{D} / \mathrm{VDBP}(\mathrm{V} 2, \mathrm{~V} 3: \mathrm{p}<0.01)$ and $1,25(\mathrm{OH})_{2} \mathrm{D} / 25(\mathrm{OH}) \mathrm{D}(\mathrm{V} 3, \mathrm{p}<0.05)$. Significance persisted after adjustment for covariates. Conclusions:In women with T1DM, concentrations of active vitamin D were higher, and VDBP lower, in the second and third trimesters in those who developed PE than in those who did not. Active vitamin D may serve as a new marker for PE risk, and could be implicated in pathogenesis.
\end{abstract}

\section{Abbreviations:}

BMI, Body Mass Index;

$\mathrm{DM}+\mathrm{PE}+$, women with type 1 diabetes who subsequently developed PE;

$\mathrm{DM}+\mathrm{PE}-$, women with type 1 diabetes who did not develop PE;

DM-, non-diabetic, normotensive women;

eGFR, Estimated glomerular filtration rate; 
HbA1c, glycated haemoglobin;

MAMPED, Markers And Mechanisms for PreEclampsia in Type 1 Diabetes;

MAP, Mean Arterial Pressure;

PE, preeclampsia;

T1DM, Type 1 diabetes mellitus;

uNGALcc, urinary neutrophil-gelatinase associated lipocalin (creatinine corrected);

VDBP, Vitamin D Binding Protein;

$1,25(\mathrm{OH})_{2} \mathrm{D}, 1,25$-dihydroxyvitamin $\mathrm{D}$;

25(OH)D, 25-hydroxyvitamin D.

Adequate levels of vitamin $\mathrm{D}$ are essential for bone health, immune function, proliferation and differentiation of cells, inflammation, insulin secretion and action, and vascular health. ${ }^{1}$ Vitamin D deficiency is common worldwide, involving genetic, lifestyle and geographical factors. ${ }^{1,2}$ Vitamin D metabolism is markedly altered during pregnancy. Specifically, for reasons not fully understood, the active metabolite 1,25-dihydroxyvitamin $\mathrm{D}\left(1,25(\mathrm{OH})_{2} \mathrm{D}\right)$ increases 2-3 fold in the first trimester, reaching concentrations that would normally be toxic, and continues to increase as pregnancy advances. ${ }^{3-5}$ Associations of active vitamin D levels with preeclampsia $(\mathrm{PE})$ in the presence of maternal diabetes have not been investigated.

In the general population, the serum concentration of 25-hydroxyvitamin $\mathrm{D}(25(\mathrm{OH}) \mathrm{D})$, the prohormone and precursor of 'active' $1,25(\mathrm{OH})_{2} \mathrm{D}$, is considered the principal metric to assess vitamin $\mathrm{D}$ status: deficiency and insufficiency are defined as $<20$ and $<32 \mathrm{ng} / \mathrm{mL}$ (50 and $80 \mathrm{nmol} / \mathrm{L}$ ), respectively. ${ }^{6}$ Vitamin D deficiency is associated with poor pregnancy outcomes for both mother and child. ${ }^{2,}$ 7-20

$\mathrm{PE}$ is a multisystem disorder defined by hypertension and proteinuria or other end-organ dysfunction, with onset after 20 weeks' gestation in a previously normotensive woman. ${ }^{21}$ Women with type 1 diabetes (T1DM) have a markedly increased risk for $\mathrm{PE} \mathrm{(} 20 \% \mathrm{vs} \sim 5 \%$ in the general population) ${ }^{22}$ Vitamin D deficiency is associated with abnormal placentation, altered angiogenesis, immune dysfunction, insulin secretion and action, adverse lipid profiles, and inflammation: problems that are also associated with diabetes. ${ }^{2}, 4,10,12-16,18,23$ Vitamin D deficiency may also be implicated in PE. ${ }^{8,12}$

We previously reported associations between PE and concentrations of fat-soluble vitamins and antioxidant pro-vitamins in women with type 1 diabetes. ${ }^{24}$ In that study, we performed only one measure of vitamin D status, 25(OH)D measured by HPLC. Women with T1DM were more likely to be vitamin D deficient than the non-diabetic group, but almost all diabetic women were deficient, and concentrations did not differ significantly according to subsequent PE status. ${ }^{24}$ Extending that work, we now investigate whether total, bioavailable, or free forms of $25(\mathrm{OH}) \mathrm{D}$, its active metabolite $1,25(\mathrm{OH})_{2} \mathrm{D}$, Vitamin D Binding Protein (VDBP) concentrations, and relevant ratios are associated with the risk for subsequent PE in women with T1DM. As before, we include a group of healthy, normotensive non-diabetic pregnant women to obtain normal reference values.

\section{Research Design and Methods}

\section{Study design and participants}

Participants in the current study are a subset of the "Markers And Mechanisms for PreEclampsia in Type 1 Diabetes" (MAMPED) cohort. MAMPED design, participant characteristics, and inclusion/exclusion criteria have been described previously. ${ }^{24-30}$ The overall goal of MAMPED was to identify early markers and potential mechanisms for PE in the context of pregnancy complicated by maternal T1DM. Briefly, it was a longitudinal, prospective pregnancy study of 151 women with T1DM and 24 non-diabetic women enrolled in the first trimester and followed until delivery. The study was conducted in Norway, Australia, and the United States, and participants were predominantly Caucasian (86\%). All were free of hypertension, 
proteinuria and microalbuminuria at enrolment (urinary albumin:creatinine ratio $<30 \mathrm{mg} / \mathrm{g}$ at the first study visit when gestational age was 9-16 weeks)). PE was defined as new-onset hypertension ( $>140 / 90 \mathrm{mmHg})$ and proteinuria (>300 mg/24 h) after 20 weeks' gestation. Clinical data and specimens (plasma, urine) were collected at three visits: first trimester (V1: gestation $12.2 \pm 1.9$ wks (mean $\pm \mathrm{SD})$ ), mid-second trimester $(\mathrm{V} 2: 21.6 \pm 1.5 \mathrm{wks})$, and early third trimester (V3: $31.5 \pm 1.7 \mathrm{wks})$. Samples were stored at $-80^{\circ} \mathrm{C}$ until analysis. The study was conducted according to Declaration of Helsinki guidelines and approved by the Institutional Review Boards at all participating institutions. Written informed consent was obtained from all participants.

In accordance with the original MAMPED design, type 1 diabetic women with PE were compared with a matched group (by age, diabetes duration, and parity) without PE. For this report, these subsets comprised 23 (of the original 26) who developed $\mathrm{PE}(\mathrm{DM}+\mathrm{PE}+$; three were unavailable through sample attrition), and 24 who remained normotensive (DM+PE-; from an original matched subset of 26). We also included 19 non-diabetic, non-PE women (DM-) as 'reference controls'. All study visits occurred prior to the onset of PE.

Medication usage was recorded at V1. All with diabetes were taking insulin. A majority were taking folic acid at V1 (DM+PE+: 70\%; DM+PE-: 71\%; DM-: 42\%, p>0.05), but overall, a minority took vitamin supplements (DM+PE+: 39\%; DM+PE-: $50 \%$; DM-: $32 \%, \mathrm{p}>0.05)$. Use of vitamin supplements did not differ by presence of diabetes, $\mathrm{PE}$ outcome, or vitamin $\mathrm{D}$ deficiency.

\section{Laboratory measures}

Vitamin D is highly lipophilic, and in plasma is almost entirely protein-bound. VDBP is the principal carrier of both $25(\mathrm{OH}) \mathrm{D}$ and $1,25(\mathrm{OH})_{2} \mathrm{D}$ (85-90\% of total): a smaller amount of each metabolite (10-15\%) is bound to albumin (a lower affinity carrier), and [?]1\% exists unbound in the 'free', biologically active form. ${ }^{31,32}$ 'Bioavailable' vitamin D is the sum of unbound (free) and albumin-bound: it is considered another useful estimate of biologically active vitamin $\mathrm{D}$ because the affinity of vitamin $\mathrm{D}$ for albumin is so low. ${ }^{31-35}$

Plasma 25(OH)D concentration was measured using the DiaSorin Corporation 25-hydroxyvitamin D ${ }^{125}$ I RIA Kit (Stillwater, MN, USA). No dilution was required. The intra- and inter-assay coefficients of variation were $[?] 10 \% .1,25(\mathrm{OH})_{2} \mathrm{D}$ was measured by Quantitative Chemiluminescent Immunoassay at ARUP laboratories, Salt Lake City, UT, after dilution 6.25-fold. VDBP was measured using the human Vitamin D BP Quantikine ELISA kit (R\&D systems, Minneapolis, MN, USA), per manufacturer's protocol: plasma samples were diluted 10,000-fold, assayed in duplicate, and intra- and inter-assay coefficients of variation were $3 \%$ and $7 \%$, respectively. Operators were masked to clinical status and sample order throughout and all samples from an individual were in the same assay run. Circulating albumin levels were measured at the Department of Clinical Biochemistry, Royal Victoria Hospital, Belfast, Northern Ireland. The levels of free and bioavailable $25(\mathrm{OH}) \mathrm{D}$ and $1,25(\mathrm{OH})_{2} \mathrm{D}$ were calculated from total measured $25(\mathrm{OH}) \mathrm{D}, 1,25(\mathrm{OH})_{2} \mathrm{D}$, VDBP and albumin concentrations using the following equations ${ }^{31,32,36}$ :

$$
\begin{gathered}
\text { Calculated free }[\mathrm{D}]=\frac{\text { Total }[\mathrm{D}]}{1+\left(K_{\mathrm{Alb}} \times[\text { Albumin }]\right)+\left(K_{\mathrm{VDBP}} \times[\mathrm{VDBP}]\right)} \\
\text { Bioavailable }[\mathrm{D}]=\left(K_{\mathrm{Alb}} \times[\text { Albumin }]+1\right) \times \text { calculated free }[\mathrm{D}] \\
\text { The percentage of free }[\mathrm{D}]=\frac{\text { Free }[\mathrm{D}]}{\text { Total }[\mathrm{D}]} \\
{[\mathrm{D}]=25(\mathrm{OH}) \mathrm{D} \text { or } 1,25(\mathrm{OH})_{2} \mathrm{D}} \\
{[\text { Albumin }]=\text { serum albumin in } \mathrm{g} / \mathrm{L} \div 66,430 \mathrm{~g} / \mathrm{mol}}
\end{gathered}
$$




$$
[\mathrm{VDBP}]=\text { serum } \mathrm{VDBP} \text { in } \mathrm{g} / \mathrm{L} \div 58,000 \mathrm{~g} / \mathrm{mol}
$$

Note that the affinity constants for albumin $\left(25(\mathrm{OH}) \mathrm{D}: \mathrm{K}_{\mathrm{Alb}}=6 \times 10^{5} \mathrm{M}^{-1} ; 1,25(\mathrm{OH})_{2} \mathrm{D}: \mathrm{K}_{\mathrm{Alb}}=5.4 \times 10^{4}\right.$ $\left.\mathrm{M}^{-1}\right)$ are substantially lower than those for $\operatorname{VDBP}\left(25(\mathrm{OH}) \mathrm{D}\right.$ : $\mathrm{K}_{\mathrm{VDBP}}=7 \times 10^{8} \quad \mathrm{M}^{-1} ; 1,25(\mathrm{OH})_{2} \mathrm{D}$ : $\left.\mathrm{K}_{\mathrm{VDBP}}=4 \times 10^{7} \mathrm{M}^{-1}\right) \cdot 31,32$

The amount of each vitamin D metabolite bound to VDBP was calculated by subtracting bioavailable from total vitamin D. Using this information, it was possible to calculate VDBP saturation for $25(\mathrm{OH}) \mathrm{D}$ and $1,25(\mathrm{OH})_{2} \mathrm{D}$.

\section{Statistical analysis}

As pre-defined in MAMPED, primary analysis compared DM+PE+ vs. DM+PE-. Secondary analyses compared 'uncomplicated' T1DM (DM+PE-) with non-diabetic women (DM-). Results were expressed as means +- SD (Tables $1 \&$ 2) or SEM (Figures 1-2). Groups were compared using unpaired Student's t tests for continuous measures and $\chi^{2}$ test for categorical measures; unpaired tests were used because of differential sample attrition. Analyses of repeated measures used Friedman's test. Logistic regression, with and without covariate adjustments, was used to estimate the probability of women with T1DM developing PE based on clinical characteristics and biomarker values. The following covariates were selected based on differences at the time of visit, and/or their known associations with vitamin D metabolism: BMI, HbA1c, and total adiponectin. ${ }^{37}$ All tests were two-tailed, with $\mathrm{p}<0.05$ considered significant. Statistical analyses were performed using SPSS software, version 22 (IBM Corp, Armonk, NY).

\section{Results}

Maternal characteristics: Table 1 shows the baseline clinical characteristics of all women. There were no significant differences in age, ethnicity, smoking, gravidity, parity, duration of T1DM, systolic and diastolic blood pressure, mean arterial pressure (MAP), total cholesterol, LDL-cholesterol, triacylglycerol, and gestational age per visit between $\mathrm{DM}+\mathrm{PE}+$ and $\mathrm{DM}+\mathrm{PE}-$. However, at the initial study visit, HbA1c, Body Mass Index (BMI) and total daily insulin dose were significantly higher in $\mathrm{DM}+\mathrm{PE}+$ than $\mathrm{DM}+\mathrm{PE}-$, and HDL-cholesterol was significantly lower. There were no significant differences between the two normotensive groups at V1, except as expected, HbA1c was higher in women with diabetes.

25(OH)D deficiency was not associated with subsequent PE in women with T1DM: Vitamin D insufficiency and deficiency are defined as $<32$ and $<20 \mathrm{ng} / \mathrm{mL}$, respectively. ${ }^{6}$ As shown in Figure 1, a majority (97\%) of all women fell below the 'normal' level of vitamin D throughout pregnancy. Women with T1DM were more likely to be $25(\mathrm{OH}) \mathrm{D}$ deficient $(\mathrm{DM}+\mathrm{PE}+: 73 \%$; DM+PE-: $65 \%)$ than non-diabetic women $(22 \%)$ at the first visit $(\mathrm{p}=0.009)$; however there were no significant differences in any measure of $25(\mathrm{OH}) \mathrm{D}$ during pregnancy between the $\mathrm{DM}+\mathrm{PE}+$ and $\mathrm{DM}+\mathrm{PE}$ - groups. Total $25(\mathrm{OH}) \mathrm{D}$ was lower in $\mathrm{DM}+\mathrm{PE}-$ than in DM- groups at the beginning of pregnancy $(\mathrm{V} 1, \mathrm{p}=0.020 ; \mathrm{V} 2, \mathrm{p}=0.034)$, but neither bioavailable nor free $25(\mathrm{OH}) \mathrm{D}$ differed by diabetes status at any visit.

Higher second and/or third trimester 1,25(OH) ${ }_{2} \mathrm{D}$ (total, bioavailable, free) are associated with subsequent $P E$ in women with T1DM: As shown in Figure 2 , in the $\mathrm{DM}+\mathrm{PE}+$ vs the $\mathrm{DM}+\mathrm{PE}$ - group, total $1,25(\mathrm{OH})_{2} \mathrm{D}$ was higher at V2 $(\mathrm{p}=0.005)$, and bioavailable and free $1,25(\mathrm{OH})_{2} \mathrm{D}$ were higher at V2 and V3 (bioavailable: $\mathrm{V} 2, \mathrm{p}=0.005$; $\mathrm{V} 3, \mathrm{p}=0.031$; free: $\mathrm{V} 2, \mathrm{p}=0.007 \& \mathrm{~V} 3, \mathrm{p}=0.009)$. In the $\mathrm{DM}+\mathrm{PE}-\mathrm{vs}$. the DM- group, all measures of $1,25(\mathrm{OH})_{2} \mathrm{D}$ were lower at V2 (total, $\mathrm{p}=0.002$; bioavailable, $\mathrm{p}=0.004$; free, $\mathrm{p}=0.018$ ). Total $1,25(\mathrm{OH})_{2} \mathrm{D}$ significantly increased as pregnancy advanced in $\mathrm{DM}+\mathrm{PE}+(\mathrm{p}<0.001)$ and $\mathrm{DM}+\mathrm{PE}-(\mathrm{p}=0.007)$.

Using logistic regression, data were analysed without and with covariates to assess the effectiveness of $1,25(\mathrm{OH})_{2} \mathrm{D}$ as a biomarker of PE. At V2, without covariates and in women with T1DM only, every 1 $\mathrm{pg} / \mathrm{mL}$ increase in total $1,25(\mathrm{OH})_{2} \mathrm{D}$ increased the odds of developing PE by $3 \%$ (OR: 1.03 (1.01-1.05), $\mathrm{p}=0.012$ ), while every $1 \mathrm{pg} / \mathrm{mL}$ increase in bioavailable $1,25(\mathrm{OH})_{2} \mathrm{D}$ increased the odds for PE by $28 \%$ (OR: $1.28(1.06-1.54), \mathrm{p}=0.010)$. Likewise, at $\mathrm{V} 3$, every $1 \mathrm{pg} / \mathrm{mL}$ increase in bioavailable $1,25(\mathrm{OH})_{2} \mathrm{D}$ increased 
the odds for PE by $18 \%$ (OR: 1.18 (1.00-1.39), p=0.047). Covariate analyses including BMI, HbA1c and total adiponectin did not affect significance.

Ratios of total, bioavailable, and free $1,25(\mathrm{OH})_{2} \mathrm{D}$ to corresponding 25(OH)D concentrations (Table 2): In the $\mathrm{DM}+\mathrm{PE}+$ vs the $\mathrm{DM}+\mathrm{PE}$ - group, total, bioavailable and free $1,25(\mathrm{OH})_{2} \mathrm{D} / 25(\mathrm{OH}) \mathrm{D}$ (product:substrate) ratios were all higher at V3 (all $\mathrm{p}<0.05$ ). There were no significant differences in these ratios at any stage of pregnancy between the DM+PE- and DM- groups, and there were no significant changes over time in any of the groups. For women with T1DM only, at V3, for every unit increase in total $1,25(\mathrm{OH})_{2} \mathrm{D} / 25(\mathrm{OH}) \mathrm{D}$, the odds of developing PE increased by $17 \%$ (OR: 1.17 (1.01-1.35), $\mathrm{p}=0.037)$, however, this significance did not persist after covariate adjustment.

Lower VDBP and higher 1,25(OH) ${ }_{2} D / V D B P$ ratio are associated with subsequent PE in women with T1DM: As summarized in Table 2, in the $\mathrm{DM}+\mathrm{PE}+$ vs the $\mathrm{DM}+\mathrm{PE}-$ group, VDBP was lower at V3 ( $\mathrm{p}=0.032)$, and total $1,25(\mathrm{OH})_{2} \mathrm{D} / \mathrm{VDBP}$ and $\left[1,25(\mathrm{OH})_{2} \mathrm{D}\right.$ bound to VDBP]/VDBP were both higher at V2 \& V3 (all $\mathrm{p}<0.01)$. Total $25(\mathrm{OH}) \mathrm{D} / \mathrm{VDBP}$ and ['25(OH)D bound to VDBP']/VDBP did not differ between $\mathrm{DM}+\mathrm{PE}+$ and $\mathrm{DM}+\mathrm{PE}-$ at any study visit. In the $\mathrm{DM}+\mathrm{PE}-$ vs the DM- group, total $1,25(\mathrm{OH})_{2} \mathrm{D} / \mathrm{VDBP}$ and [ ${ }^{1} 1,25(\mathrm{OH})_{2} \mathrm{D}$ bound to VDBP']/VDBP were lower at $\mathrm{V} 2(\mathrm{p}=0.025$ and $\mathrm{p}=0.018$ respectively). VDBP significantly increased throughout pregnancy in all groups (all $\mathrm{p}<0.001$ ). For women with T1DM only, for every $1 \mathrm{mg} / \mathrm{dL}$ increase in VDBP at V3, the odds of developing PE decreased by 8\% (OR: $0.92(0.85-$ 1.00), $\mathrm{p}<0.05)$. At $\mathrm{V} 2$, for every unit increase in total $1,25(\mathrm{OH})_{2} \mathrm{D} / \mathrm{VDBP}$, the odds of developing $\mathrm{PE}$ increased almost three-fold (OR: $2.71(1.28-5.77), \mathrm{p}=0.009)$. Likewise, at V3, for every unit increase in total $1,25(\mathrm{OH})_{2} \mathrm{D} / \mathrm{VDBP}$, the odds of developing PE increased similarly (OR: 2.53 (1.21-5.29), $\mathrm{p}=0.013$ ). Consideration of covariates had no effect.

\section{Discussion}

Main findings: This longitudinal study of pregnancy in T1DM is the first to report multiple detailed measures of vitamin D (total, bioavailable and free concentrations of $25(\mathrm{OH}) \mathrm{D}$ and $1,25(\mathrm{OH})_{2} \mathrm{D}$; VDBP; relevant ratios), and their associations with subsequent PE. We were surprised to find that at V2 and V3, elevated plasma 'active' $1,25(\mathrm{OH})_{2} \mathrm{D}$, low VDBP, and elevated $1,25(\mathrm{OH})_{2} \mathrm{D}$ :VDBP ratios were associated with subsequent $\mathrm{PE}$.

In contrast, $25(\mathrm{OH}) \mathrm{D}$, the standard metric of vitamin $\mathrm{D}$, did not predict PE; of note, however, insufficient or deficient levels were almost universal in our diabetic cohort. Reported associations of vitamin D deficiency in diabetic pregnancy include preterm birth, increased T1DM rates in offspring of women with T1DM, and poor glycaemic control. ${ }^{11}, 16,19,20,23$ Some studies of non-diabetic pregnant women have suggested associations between low total $25(\mathrm{OH}) \mathrm{D}$ and contemporaneous ${ }^{9}$ or subsequent $\mathrm{PE},{ }^{8}, 11$ perhaps limited to early-onset disease. ${ }^{12}$ Our present finding of no significant association is consistent with our previous study (that used different methodology to measure $25(\mathrm{OH}) \mathrm{D}),{ }^{24}$ and with a study by Vestgaard et al .. ${ }^{16}$ The present work extends those findings by showing that, like total $25(\mathrm{OH}) \mathrm{D}$, neither bioavailable nor free forms of $25(\mathrm{OH}) \mathrm{D}$ were predictive of PE. Again, there is the caveat that our cohort did not contain vitamin D-sufficient women.

Maternal 'active vitamin D' $\left(1,25(\mathrm{OH})_{2} \mathrm{D}\right)$ concentrations are known to increase markedly throughout normal pregnancy compared with normal, non-pregnant values, ${ }^{38}$ reaching levels that would be toxic in other circumstances. This phenomenon is recognized but not fully understood. Other studies of active vitamin D throughout pregnancy are sparse, and there is none in the context of maternal diabetes. A smaller longitudinal case-control study of PE in non-diabetic pregnancy (10 PE cases vs 40 controls) found no association between serum $1,25(\mathrm{OH})_{2} \mathrm{D}$ in late second and early third trimesters and subsequent PE. ${ }^{7}$ In contrast, we found that bioavailable and free $1,25(\mathrm{OH})_{2} \mathrm{D}$ both predict $\mathrm{PE}$ at the second and early third trimesters, while total $1,25(\mathrm{OH})_{2} \mathrm{D}$ predicted $\mathrm{PE}$ at the second trimester. The pregnancy-associated increase in active vitamin $\mathrm{D}$ is known to be accompanied by, but disproportionate to, an increase in VDBP, and a change in binding affinity has been suggested. ${ }^{38,}{ }^{39} \mathrm{High} 1,25(\mathrm{OH})_{2} \mathrm{D}$ is thought to reflect the calcium needs of the developing foetus, increasing calcium absorption and up-regulating trans-placental transport. ${ }^{39}$

Lower VDBP concentrations were predictive of $\mathrm{PE}$ at the third trimester, and the ratio of $1,25(\mathrm{OH})_{2} \mathrm{D} / \mathrm{VDBP}$ 
was predictive at V2 and V3. A larger study is needed to determine whether this ratio is a better predictor than $1,25(\mathrm{OH})_{2} \mathrm{D}$ alone. VDBP, like many plasma proteins, significantly increased as pregnancy advanced, independent of diabetes or PE status.

Strengths and Limitations: In this study, we measure not only $25(\mathrm{OH}) \mathrm{D}$, but also active $1,25(\mathrm{OH})_{2} \mathrm{D}$ and VDBP in a longitudinal study of T1DM women with and without (late-onset) PE. We include estimates of bioavailable and free concentrations. Our cohort, although small, was rigorously phenotyped, and was free of proteinuria and hypertension at enrolment. Gestational time-points were well-defined, and all study visits were prior to $\mathrm{PE}$ onset. A non-diabetic control group provided reference values for normal pregnancy.

Limitations include reliance on affinity constants to estimate free forms of vitamin D: these constants may vary between individuals, and may be altered by pregnancy. ${ }^{38}$ Our cohort was predominantly Caucasian, and there are ethnic differences in vitamin D metabolism and function, including variation of VDBP allelic forms according to race. ${ }^{40,41}$ Sunshine exposure affects total $25(\mathrm{OH}) \mathrm{D}$ levels, and vitamin D deficiency may have seasonal and geographical variations. In our subset, $51 \%$ of the women were from Norway, $29 \%$ from Australia, and $20 \%$ from USA. Small numbers precluded stratification by season or location, but most participants, regardless of origin, were vitamin D insufficient or deficient. The absence of vitamin D-sufficient women is a limitation.

Interpretation: Vitamin D is converted from pro-hormone, $25(\mathrm{OH}) \mathrm{D}$, to active hormone by $25(\mathrm{OH}) \mathrm{D}-1 \alpha-$ hydroxylase, predominantly in the kidney, but also in macrophages and, during pregnancy, in the placenta. ${ }^{42}$ Higher levels of 'active vitamin D' in diabetic women with subsequent PE could reflect early subclinical renal or placental dysfunction. The kidney is the major site of its formation, and furthermore, VDBP is filtered through the glomerulus and is reabsorbed by the proximal tubules. ${ }^{2}{ }^{36}$ We may hypothesise that early renal dysfunction, prior to PE onset, perturbs both $1,25(\mathrm{OH})_{2} \mathrm{D}$ and VDBP. ${ }^{43,}{ }^{44}$ Women were excluded from our study if they had microalbuminuria or more severe albuminuria at V1. Nevertheless, other evidence from the MAMPED cohort supports the concept that subtle, early renal abnormalities confer PE risk: specifically increased first trimester urinary neutrophil-gelatinase associated lipocalin (creatinine corrected) (uNGALcc) and elevated 'estimated glomerular filtration rates' (eGFR). ${ }^{29}$ Relating current data to these prior findings, we observed, specifically in $\mathrm{DM}+\mathrm{PE}+$ women at first trimester, that total, bioavailable and free $25(\mathrm{OH}) \mathrm{D}$ were negatively correlated with eGFR (all $\mathrm{p}<0.05)$, while total and free $1,25(\mathrm{OH})_{2} \mathrm{D}$ at V2 were positively correlated with uNGALcc $(\mathrm{p}<0.05)$. Regarding VDBP, any renal insult during or even before pregnancy could alter glomerular and tubular processing. Overall, these lines of evidence support the notion that subtle subclinical renal dysfunction, preceding microalbuminuria, is associated with PE.

An alternative possibility is that the association between active vitamin D and subsequent PE is 'defensive', a response to early stresses initiating disease. Active vitamin D has protective functions for the fetoplacental unit, inhibiting inflammatory cytokines ${ }^{45}$ and inducing anti-microbial peptide synthesis. ${ }^{46}$ In a rat model (reduced utero-placental perfusion, RUPP), treatment of animals with $1,25(\mathrm{OH})_{2} \mathrm{D}$ early in gestation ameliorated PE, apparently by reducing oxidative and ER stresses; ${ }^{47}$ and in a cross-sectional study in nondiabetic humans, plasma $1,25(\mathrm{OH})_{2} \mathrm{D}$ was lower in those with than without $\mathrm{PE},{ }^{48}$ perhaps reflecting defeat of protective responses.

Associations between vitamin D and PE may differ between 'mild, late onset' PE and 'early-onset severe' form of the disease, and Bodnaret al. have suggested that the association between vitamin D deficiency and $\mathrm{PE}$ is limited to the latter. ${ }^{12}$ In the present prospective study, an overwhelming majority ( $\left.290 \%\right)$ of PE cases in T1DM women were 'mild, late onset'. A prospective study of early-onset, severe disease was beyond the scope of MAMPED.

Whether any of the associations we have identified reflect a causal relationship, and how they might be affected by vitamin D supplementation is unknown. Currently, during pregnancy, all women are recommended to take $600 \mathrm{IU}$ vitamin $\mathrm{D}$ daily, ${ }^{6}$ but a recent study shows that 4,000 IU daily is more effective at maintaining sufficiency without toxicity. ${ }^{3}$ Whether supplementation reduces PE risk for women with diabetes is unknown: a recent multicentre study to assess efficacy in preventing GDM showed a marginal reduction 
in fasting glucose, but was underpowered to address PE. ${ }^{49}$ In that study, and in contrast to our T1DM patients, women were largely vitamin D sufficient at study entry. ${ }^{50}$ Studies of effects of vitamin D on human hypertension have yielded generally negative results. ${ }^{49}$

Conclusion: This is the first longitudinal, observational study to investigate associations of vitamin D metabolites and VDBP with PE in women with T1DM. In the late second trimester, $1,25(\mathrm{OH})_{2} \mathrm{D}$ and $1,25(\mathrm{OH})_{2} \mathrm{D} / \mathrm{VDBP}$ ratio were good predictors of PE. Further studies should address the value of these biomarkers, the significance of differential changes of $25(\mathrm{OH}) \mathrm{D}$ and $1,25(\mathrm{OH})_{2} \mathrm{D}$ during pregnancy, mechanistic implications, and whether optimising vitamin $\mathrm{D}$ status during pregnancy is effective in reducing the high prevalence of PE in T1DM women.

\section{Article Information.}

Acknowledgements: The skilled and dedicated assistance of the following individuals for the clinical components of the study is acknowledged, none of whom were compensated for their contributions: Spartanburg Regional Hospital, Spartanburg, SC: Jill Cole; University of Melbourne, Australia: Christine Knight, Dr Jennifer Conn, Susan Hiscock, Dr Jeremy Oats, Peter Wein; University of Oklahoma, Oklahoma City, OK: Azar Dashti.

Declaration of interests: The authors have declared that no conflicts of interest exist.

Ethics approval: The study was approved by the Institutional Review Boards of all the participating institutions and by the Ethics Committee of the Medical University of South Carolina (IRB\#: 81076, Date: Aug 14, 2018); it was conducted according to the principles of the Declaration of Helsinki.

Data Availability: The data that support the findings of this study are available from the corresponding author on reasonable request.

Funding/Sponsor: This work was supported by Research Grants from the Juvenile Diabetes Research Foundation (JDRF 1-2001-844), and Novo Nordisk to TJL, and by NIH (NCRR) Grants M01-RR-1070 and M01 RR-14467 to the General Clinical Research Centers at MUSC and OUHSC respectively. Support from Novo Nordisk enabled the participation of the Barbara Davis Diabetes Center for Childhood Diabetes at the University of Colorado.

Role of the Funder/Sponsor: The sponsors had no role in the design and conduct of the study; collection, management, analysis, and interpretation of the data; preparation, review, or approval of the manuscript; and decision to submit the manuscript for publication.

\section{Author Contributions:}

Timothy J. Lyons had full access to all of the data in the study and takes responsibility for the integrity of the data and the accuracy of the data analysis.

Study concept and design: Kelly, Wagner, Shary, Leyva, Yu, Jenkins, Nankervis, Hanssen, Garg, Scardo, Hammad, Aston, Lyons.

Drafting of the manuscript: Kelly, Lyons .

Statistical analysis: Kelly, Lyons.

Reviewed/edited the manuscript: Wagner, Shary, Leyva, Yu, Jenkins, Nankervis, Hanssen, Garg, Scardo, Hammad, Aston,

Obtained funding: Lyons.

Study supervision: Lyons.

\section{References}


1. Roth DE, Abrams SA, Aloia J, Bergeron G, Bourassa MW, Brown KH, et al. Global prevalence and disease burden of vitamin D deficiency: a roadmap for action in low- and middle-income countries. Ann N Y Acad Sci. 2018;1430:44-79.

2. Hossein-nezhad A, Holick MF. Vitamin D for health: a global perspective. Mayo Clin Proc. 2013;88:720-755. doi:10.1016/j.mayocp.2013.05.011.

3. Hollis BW, Johnson D, Hulsey TC, Ebeling M, Wagner CL. Vitamin D supplementation during pregnancy: double-blind, randomized clinical trial of safety and effectiveness. J Bone Miner Res . 2011;26:2341-2357. doi:10.1002/jbmr.463.

4. Ganguly A, Tamblyn JA, Finn-Sell S, Chan SY, Westwood M, Gupta J, et al. Vitamin D, the placenta and early pregnancy: effects on trophoblast function. J Endocrinol . 2018;236(2):R93-r103. doi:10.1530/JOE-17-0491.

5. Kumar R, Cohen WR, Silva P, Epstein FH. Elevated 1,25-dihydroxyvitamin D plasma levels in normal human pregnancy and lactation. J Clin Invest . 1979;63:342-344. 10.1172/jci109308

6. Institute of Medicine Committee to Review Dietary Reference Intakes for Vitamin D, Calcium: Dietary Reference Intakes for Calcium and Vitamin D. Ross AC, Taylor CL, Yaktine AL, Del Valle HB, Eds. Washington (DC), National Academies Press (US). National Academy of Sciences, 2011

7. Halhali A, Villa AR, Madrazo E, Soria MC, Mercado E, Diaz L, et al. Longitudinal changes in maternal serum 1,25-dihydroxyvitamin D and insulin like growth factor I levels in pregnant women who developed preeclampsia: comparison with normotensive pregnant women. J Steroid Biochem Mol Biol. 2004;89-90(1-5):553-556. 10.1016/j.jsbmb.2004.03.069

8. Bodnar LM, Catov JM, Simhan HN, Holick MF, Powers RW, Roberts JM. Maternal vitamin D deficiency increases the risk of preeclampsia. J Clin Endocrinol Metab 2007;92: 3517-3522. 10.1210/jc.20070718

9. Robinson CJ, Alanis MC, Wagner CL, Hollis BW, Johnson DD. Plasma 25-hydroxyvitamin D levels in early-onset severe preeclampsia.Am J Obstet Gynecol. 2010;203:366.e361-366. doi:10.1016/j.ajog.2010.06.036.

10. Ma R, Gu Y, Zhao S, Sun J, Groome LJ, Wang Y. Expressions of vitamin D metabolic components VDBP, CYP2R1, CYP27B1, CYP24A1, and VDR in placentas from normal and preeclamptic pregnancies. Am J Physiol Endocrinol Metab. 2012;303:E928-935. doi:10.1152/ajpendo.00279.2012.

11. Wei SQ, Audibert F, Hidiroglou N, Sarafin K, Julien P, Wu Y, et al. Longitudinal vitamin D status in pregnancy and the risk of pre-eclampsia. BJOG . 2012;119:832-839. doi:10.1111/j.14710528.2012.03307.x.

12. Bodnar LM, Simhan HN, Catov JM, Roberts JM, Platt RW, Diesel JC, et al. Maternal vitamin D status and the risk of mild and severe preeclampsia. Epidemiology. 2014;25:207-214. doi:10.1097/EDE.0000000000000039.

13. Smith TA, Kirkpatrick DR, Kovilam O, Agrawal DK. Immunomodulatory role of vitamin $\mathrm{D}$ in the pathogenesis of preeclampsia. Expert Rev Clin Immunol. 2015;11:1055-1063. doi:10.1586/1744666X.2015.1056780.

14. Kiely ME, Zhang JY, Kinsella M, Khashan AS, Kenny LC. Vitamin D status is associated with uteroplacental dysfunction indicated by pre-eclampsia and small-for-gestational-age birth in a large prospective pregnancy cohort in Ireland with low vitamin D status. Am J Clin Nutr. 2016;104:354-361. doi:10.3945/ajcn.116.130419.

15. Tamblyn JA, Susarla R, Jenkinson C, Jeffery LE, Ohizua O, Chun RF, et al. Dysregulation of maternal and placental vitamin D metabolism in preeclampsia. Placenta. 2017;50:70-77. doi:10.1016/j.placenta.2016.12.019.

16. Vestgaard M, Secher AL, Ringholm L, Jensen JB, Damm P, Mathiesen ER. Vitamin D insufficiency, preterm delivery and preeclampsia in women with type 1 diabetes - an observational study. Acta Obstet Gynecol Scand . 2017;96:1197-1204. doi:10.1111/aogs.13180.

17. Mirzakhani H, Carey VJ, McElrath TF, Laranjo N, O'Connor G, Iverson RE, et al. The Association of Maternal Asthma and Early Pregnancy Vitamin D with Risk of Preeclampsia: An Observation From Vitamin D Antenatal Asthma Reduction Trial (VDAART). J Allergy Clin Immunol Pract . 
2018;6:600-608.e602. doi:10.1016/j.jaip.2017.07.018.

18. O'Callaghan KM, Kiely M. Systematic Review of Vitamin D and Hypertensive Disorders of Pregnancy. Nutrients. 2018;10. doi:10.3390/nu10030294.

19. Mäkinen M, Löyttyniemi E, Koskinen M, Vähä-Mäkilä M, Siljander H, Nurmio M, et al. Serum 25Hydroxyvitamin D Concentrations at Birth in Children Screened for HLA-DQB1 Conferred Risk for Type 1 Diabetes.J Clin Endocrinol Metab . 2019;104:2277-2285. doi:10.1210/jc.2018-02094.

20. Tapia G, Marild K, Dahl SR, Lund-Blix NA, Viken MK, Lie BA, et al. Maternal and Newborn Vitamin D-Binding Protein, Vitamin D Levels, Vitamin D Receptor Genotype, and Childhood Type 1 Diabetes.Diabetes Care . 2019;42:553-559. doi:10.2337/dc18-2176.

21. American College of Obstetricians and Gynecologists; Task Force on Hypertension in Pregnancy Report. Obstet Gynecol.2013;122:1122-1131. doi:10.1097/01.AOG.0000437382.03963.88.

22. Persson M, Norman M, Hanson U. Obstetric and perinatal outcomes in type 1 diabetic pregnancies: A large, population-based study.Diabetes Care . 2009;32:2005-2009. doi:10.2337/dc09-0656.

23. Bennett SE, McPeake J, McCance DR, Manderson JG, Johnston P, McGalliard R, et al. Maternal vitamin D status in type 1 diabetic pregnancy: impact on neonatal vitamin D status and association with maternal glycaemic control. PLoS One. 2013;8:e74068. doi:10.1371/journal.pone.0074068.

24. Azar M, Basu A, Jenkins AJ, Nankervis AJ, Hanssen KF, Scholz H, et al. Serum carotenoids and fat-soluble vitamins in women with type 1 diabetes and preeclampsia: a longitudinal study. Diabetes Care . 2011;34:1258-1264. doi:10.2337/dc10-2145.

25. Yu Y, Jenkins AJ, Nankervis AJ, Hanssen KF, Scholz H, Henriksen T, et al. Anti-angiogenic factors and pre-eclampsia in type 1 diabetic women. Diabetologia . 2009;52:160-168. doi:10.1007/s00125-008$1182-\mathrm{x}$.

26. Du M, Basu A, Fu D, Wu M, Centola M, Jenkins AJ, et al. Serum inflammatory markers and preeclampsia in type 1 diabetes: a prospective study. Diabetes Care. 2013;36:2054-2061. doi:10.2337/dc12-1934.

27. Basu A, Yu JY, Jenkins AJ, Nankervis AJ, Hanssen KF, Henriksen T, et al. Trace elements as predictors of preeclampsia in type 1 diabetic pregnancy. Nutr Res. 2015;35:421-430. doi:10.1016/j.nutres.2015.04.004.

28. Kelly CB, Hookham MB, Yu JY, Lockhart SM, Du M, Jenkins AJ, et al. Circulating adipokines are associated with pre-eclampsia in women with type 1 diabetes. Diabetologia. 2017;60:2514-2524. doi:10.1007/s00125-017-4415-z.

29. Kelly CB, Hookham MB, Yu JY, Jenkins AJ, Nankervis AJ, Hanssen KF, et al. Subclinical First Trimester Renal Abnormalities Are Associated With Preeclampsia in Normoalbuminuric Women With Type 1 Diabetes.Diabetes Care . 2018;41:120-127. doi:10.2337/dc17-1635.

30. Kelly CB, Yu JY, Jenkins AJ, Nankervis AJ, Hanssen KF, Garg SK, et al. Haptoglobin phenotype modulates lipoprotein-associated risk for preeclampsia in women with Type 1 diabetes. J Clin Endocrinol Metab . 2019;104:4743-4755. doi:10.1210/jc.2019-00723.

31. Bikle DD, Siiteri PK, Ryzen E, Haddad JG. Serum protein binding of 1,25-dihydroxyvitamin D: a reevaluation by direct measurement of free metabolite levels. J Clin. Endocrinol Metab. 1985;61:969975. doi :10.1210/jcem-61-5-969

32. Bikle DD, Gee E, Halloran B, Kowalski MA, Ryzen E, Haddad JG. Assessment of the free fraction of 25-hydroxyvitamin $\mathrm{D}$ in serum and its regulation by albumin and the vitamin D-binding protein. $J$ Clin. Endocrinol Metab. 1986;63:954-959. doi:10.1210/jcem-63-4-954

33. Chun RF, Peercy BE, Orwoll ES, Nielson CM, Adams JS, Hewison M. Vitamin D and DBP: The free hormone hypothesis revisited. J Steroid Biochem Mol Biol. 2014;144:132-137. doi:10.1016/j.jsbmb.2013.09.012.

34. Schwartz JB, Lai J, Lizaola B, Kane L, Weyland P, Terrault NA, et al. Variability in free 25(OH) vitamin D levels in clinical populations.J Steroid Biochem Mol Biol. 2014;144 Pt A:156-158. doi:10.1016/j.jsbmb.2013.11.006.

35. Yu C, Xue H, Wang L, Chen Q, Chen X, Zhang Y, et al. Serum Bioavailable and Free 25-Hydroxyvitamin D Levels, but Not Its Total Level, Are Associated With the Risk of Mortality in Patients With Coronary Artery Disease. Circ Res. 2018;123:996-1007. 
doi:10.1161/CIRCRESAHA.118.313558.

36. Bhan I, Powe CE, Berg AH, Ankers E, Wenger JB, Karumanchi SA, et al. Bioavailable vitamin D is more tightly linked to mineral metabolism than total vitamin $\mathrm{D}$ in incident hemodialysis patients. Kidney Int. 2012;82:84-89. doi:10.1038/ki.2012.19

37. Karras SN, Polyzos SA, Newton DA, Wagner CL, Hollis BW, Ouweland JVD, et al. Adiponectin and vitamin D-binding protein are independently associated at birth in both mothers and neonates. Endocrine . 2018;59:164-174. 10.1007/s12020-017-1475-2

38. Bikle DD, Gee E, Halloran B, Haddad JG. Free 1,25-dihydroxyvitamin D levels in serum from normal subjects, pregnant subjects, and subjects with liver disease. J Clin Invest. 1984;74:1966-1971. doi: 10.1172/JCI111617

39. Bouillon R. Chapter 5 - The Vitamin D Binding Protein DBP. In: Feldman D, Pike JW, Adams JS (eds) Vitamin D (Third Edition). Academic Press, San Diego, pp 57-72; 2011.

40. Newton DA, Baatz JE, Kindy MS, Gattoni-Celli S, Shary JR, Hollis BW, et al. Vitamin D binding protein polymorphisms significantly impact vitamin D status in children. Pediatric Res.2019;86(5):662669. doi:10.1038/s41390-019-0322-y.

41. Hollis BW, Pittard WB, $3^{\text {rd }}$. Evaluation of the total fetomaternal vitamin D relationships at term: evidence for racial differences. J Clin Endocinol Metab. 1984;59:652-657. doi:10.1210/jcem-59-4-652

42. Adams JS, Hewison M. Extrarenal expression of the 25-hydroxyvitamin D-1-hydroxylase. Arch Biochem Biophys. 2012;523(1): 95-102. 10.1016/j.abb.2012.02.016

43. Al-Badr W, Martin KJ. Vitamin D and kidney disease. Clin J Am Soc Nephrol. 2008;3:1555-1560. doi:10.2215/CJN.01150308.

44. Kim CS, Kim SW. Vitamin D and chronic kidney disease. Korean J Intern Med. 2014;29:416-427. doi:10.3904/kjim.2014.29.4.416.

45. Noyola-Martinez N, Diaz L, Avila E, Halhali A, Larrea F, Barrera D. Calcitriol downregulates TNFalpha and IL-6 expression in cultured placental cells from preeclamptic women. Cytokine . 2013;61: 245-250. 10.1016/j.cyto.2012.10.001

46. Olmos-Ortiz A, Noyola-Martinez N, Barrera D, Zaga-Clavellina V, Avila E, Halhali A, et al. IL10 inhibits while calcitriol reestablishes placental antimicrobial peptides gene expression. J Steroid Biochem Mol Biol. 2015;148: 187-193. 10.1016/j.jsbmb.2014.07.012

47. Tian X, Ma S, Wang Y, Hou L, Shi Y, Yoa M, et al. Effects of Placental Ischemia Are Attenuated by 1,25-Dihydroxyvitamin D Treatment and Associated with Reduced Apoptosis and Increased Autophagy. DNA Cell Biol 2016;35: 59-70. doi:10.1089/dna.2015.2885

48. August P, Marcaccio B, Gertner JM, Druzin ML, Resnick LM, Laragh JH. Abnormal 1,25dihydroxyvitamin D metabolism in preeclampsia. Am J Obstet Gynecol . 1992;166: 1295-1299. doi:10.1016/s0002-9378(11)90625-5

49. Legarth C, Grimm D, Wehland M, Bauer J, Kruger M. The Impact of Vitamin D in the Treatment of Essential Hypertension. Int J Mol Sci. 2018;19. doi:10.3390/ijms19020455

50. Corcoy R, Mendoza LC, Simmons D, Desoye G, Adelantado JM, Chico A, et al. The DALI vitamin D randomized controlled trial for gestational diabetes mellitus prevention: No major benefit shown besides vitamin D sufficiency. Clin Nutr. 2020;39: 976-984. 10.1016/j.clnu.2019.04.006

\section{Hosted file}

Kelly et al. Vit D Tables 1 \& 2 BJOG.docx available at https://authorea.com/users/324802/ articles/452900-vitamin-d-metabolites-and-binding-protein-predict-preeclampsia-in-womenwith-type-1-diabetes-a-cohort-study 

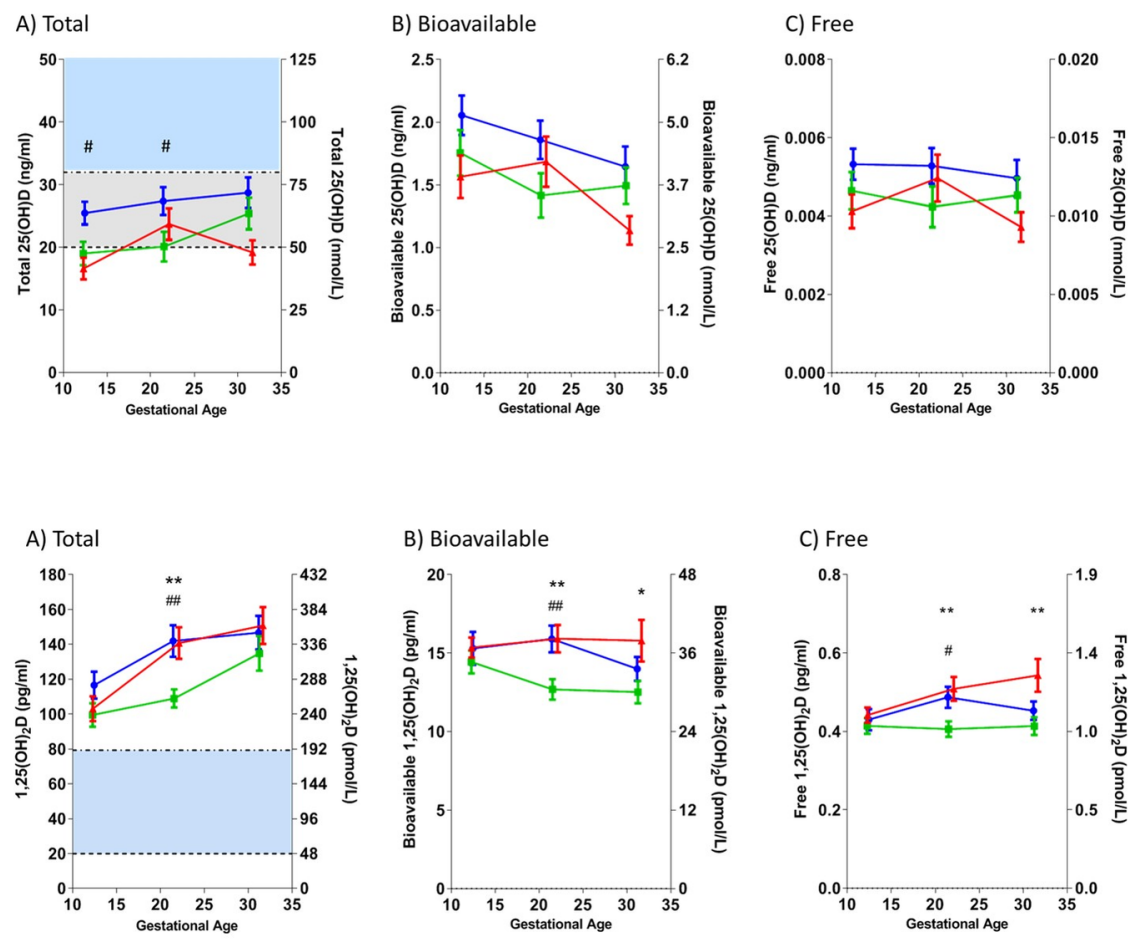